\title{
REFORMA DA UNIVERSIDADE NO CONTEXTO DA INTEGRAÇÃO EUROPEIA: O PROCESSO DE BOLONHA E SEUS DESDOBRAMENTOS
}

\author{
Maria Creusa de Araújo Borges*
}

\begin{abstract}
RESUMO: A integração europeia na perspectiva educacional - a construção da Área Europeia de Ensino Superior e de Investigação - inicia-se por intermédio do Processo de Bolonha, cujo documento-símbolo, a Declaração de Bolonha (1999), imprime uma nova direção à reforma das instituições de ensino superior e das universidades. Nesse contexto, as tarefas das universidades são reformuladas no sentido da produção da inovação tecnológica e da formação de novas competências para o mundo do trabalho, tarefas requeridas pelo desenvolvimento econômico ora em curso, pautado em processos de globalização e na centralidade do conhecimento no setor produtivo.
\end{abstract}

Palavras-chave: Processo de Bolonha. Área europeia de ensino superior. Europa do Conhecimento. Reforma da universidade.

\section{UNIVERSITY REFORM IN THE CONTEXT OF EUROPEAN INTEGRATION: the Bologna Process ANd its Developments}

ABSTRACT: The European integration in educational perspective - the construction of the European Area of Higher Education and Research - starts through the Bologna Process, whose symbolic document, the Bologna Declaration (1999) stamps a new direction to the reform of higher education institutions and universities. In this context, the tasks of universities are refined in the sense of the production of technological innovation and training of new skills to the work environment, tasks required for economic development now under way, guided by the globalization process and the centrality of knowledge in the productive sector.

Key words: Bologna Process. European area of higher education. Europe of knowledge. University reform.

Doutora em Sociologia e professora do Centro de Educação e dos Programas de Pós-Graduação em Ciências Jurídicas e em Educação da Universidade Federal da Paraíba (UFPB).

E-mail: mcaborges@gmail.com 


\title{
REFORME DE L' UNIVERSITE DANS LE CONTEXTE DE L'INTEGRATION europeenne: le Processus de Bologne et Ses deploiements
}

\begin{abstract}
RÉSUMÉ: l'intégration européenne dans la perspective éducationnelle la construction de l'Aire Européenne de l'Enseignement Supérieur et de l'Investigation - commence par l'intermédiaire du Processus de Bologne, dont le document-symbole, la Déclaration de Bologne (1999), imprime une nouvelle direction à la réforme des institutions de l'enseignement supérieur et des universités. Dans ce contexte, les tâches des universités sont reformulées au sens de la production de l'innovation technologique et de la formation de nouvelles compétences pour le monde du travail, tâches requises par le développement économique, néanmoins sous forme de cours orientés sur les processus de globalisation et sur la centralité de la connaîssance dans le secteur productif .
\end{abstract}

Mots-clés: Processus de Bologne. Aire européenne de l'enseignement supérieur. Europe de la connaîssance. Réforme de l'université.

\section{Os antecedentes do Processo de Bolonha}

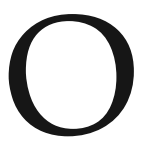

debate sobre a construção da Área Europeia de Ensino Superior toma impulso decisivo a partir das atividades empreendidas no âmbito do Processo de Bolonha. ${ }^{1}$ Entretanto, a discussão de alguns documentos precursores é fundamental para a análise da integração europeia na perspectiva educacional. Assim, são examinados os documentos Magna Charta Universitatum (1988) e a Declaração de Sorbonne (1998).

A discussão de algumas temáticas, presentes nos discursos construídos a partir da Declaração de Bolonha (1999), é antecipada nos documentos supracitados, sendo necessária, portanto, a análise desses documentos no que diz respeito, sobretudo, às temáticas colocadas na agenda de discussão, às concepções de universidade e às recomendações sugeridas.

No documento Magna Charta Universitatum, assinado pelos reitores das universidades europeias, discute-se o papelda universidade numa sociedade em mudança e internacional, antecipando uma discussão recorrente nos documentos construídos a partir do contexto do Processo de Bolonha. ${ }^{2}$ Numa sociedade marcada por processos de globalização e onde o conhecimento se constitui numa mercadoria de grande valor, as instituições de ensino superior e as universidades são chamadas a desempenhar novos papéis, diante das demandas criadas por essa sociedade, sobretudo aquelas referentes às necessidades do mercado de trabalho e de desenvolvimento da economia europeia.

No contexto europeu, a discussão sobre a construção da Europa do Conhecimento coloca novos desafios para a universidade, sendo esta chamada a contribuir 
no processo de integração europeia nos aspectos culturais, sociais e, principalmente, no desenvolvimento econômico. ${ }^{3}$ No referido documento, embora ter sido elaborado em 1988, encontra-se presente a discussão do papel da universidade no processo de desenvolvimento econômico, temática enfatizada e reiterada nos discursos construídos sobre a instituição universitária a partir da Declaração de Bolonha (1999) e, também, nos discursos das organizações internacionais, sobretudo do Banco Internacional de Reconstrução e Desenvolvimento (Bird) e da Organização Mundial do Comércio (OMC). ${ }^{4}$

No documento em análise, as universidades são definidas como centros de cultura, conhecimento e pesquisa, e são guiadas pelos princípios da autonomia; produção do conhecimento; unidade entre ensino e pesquisa; independência em relação às autoridades externas, tanto econômicas como políticas; liberdade acadêmica. Trata-se de uma concepção de universidade pautada em princípios republicanos, que enfatizam a autonomia, a liberdade acadêmica como aspectos que distinguem uma instituição como universidade.

Com base nessa concepção, os reitores das universidades europeias sugerem recomendações, tais como: contratação de professores, com ênfase na inseparabilidade da pesquisa e do ensino como critério de contratação; necessidade de congregação de projetos, garantindo-se a troca de informações e documentos como base para a realização do progresso da produção do conhecimento e dos processos de aprendizagem; mobilidade de professores e alunos, sendo necessária uma política de equivalência de estatuto, de títulos e de exames para efetivar essa mobilidade e a necessidade de a instituição universitária transcender barreiras geográficas e políticas. Nessa concepção, encontram-se presentes características mais próximas de um modelo humboldtiano de instituição universitária, que enfatiza a produção de pesquisa como aspecto fundamental e que distingue uma instituição como universidade. As temáticas unidade ensino e pesquisa, mobilidade, política de equivalência e integração europeia são discutidas no Processo de Bolonha, sendo trabalhadas de forma mais detalhada e até ampliadas com a finalidade de concretização da Área Europeia de Ensino Superior e da Europa do conhecimento.

Com algumas nuanças, na Declaração de Sorbonne (1998), documento construído por ministros de educação europeus (Alemanha, França, Itália e Reino Unido), dez anos após a elaboração do documento Magna Charta Universitatum, é colocado o discurso do papel da universidade na construção das dimensões intelectuais, culturais, sociais e técnicas do continente europeu. Nesse sentido, o papel da universidade é ampliado para além da dimensão da produção do conhecimento, sendo chamada, no contexto de uma sociedade cada vez mais internacional, a desempenhar papéis referentes a outras dimensões, sobretudo quanto aos aspectos relativos 
ao processo de desenvolvimento social e econômico e à construção da Europa do conhecimento.

Nesse contexto, algumas recomendações são indicadas: circulação livre de estudantes e professores; abolição das barreiras para concretizar a mobilidade e a cooperação no espaço europeu de ensino superior; reconhecimento internacional dos sistemas de ensino superior europeus. Para a efetivação da mobilidade são colocadas como propostas a utilização do esquema de créditos European Credit Transfer System (ECTS), ${ }^{5}$ tanto para a troca como para a acumulação, e a organização dos graus acadêmicos em dois ciclos principais, com a finalidade de facilitar comparações e equivalências de títulos.

Percebe-se que, no documento em análise, a concepção de universidade trabalhada se insere no contexto da integração europeia. Trata-se de uma concepção que enfatiza o papel da universidade no âmbito de uma sociedade cada vez mais globalizada e pautada no conhecimento. Nesse contexto, as instituições universitárias são chamadas a exercerem papéis referentes, sobretudo, à formação de cidadãos qualificados para o mercado de trabalho, oferecendo as competências necessárias às demandas desse mercado. Outra exigência feita à universidade diz respeito à produção de conhecimento na perspectiva das necessidades do setor produtivo. Dessa forma, a universidade é pressionada a desenvolver a pesquisa aplicada, vinculada aos imperativos do desenvolvimento econômico, sendo, inclusive, utilizada a sua capacidade de produzir inovação tecnológica como critério de avaliação da instituição.

Nos documentos Magna Charta Universitatum e Declaração de Sorbonne são realçadas concepções de universidade na perspectiva de construção de uma Europa mais ampliada, nas dimensões sociais, econômicas, técnicas e culturais. Nesse contexto, as instituições universitárias são pressionadas a exercerem papéis diferentes ${ }^{6}$ daqueles que estão acostumadas a desempenhar, para além da produção do conhecimento e do ensino. A questão que se coloca se constitui, fundamentalmente, na produção de produtos universitários voltados para o desenvolvimento da economia europeia, contribuindo para a melhoria de sua competitividade no mundo todo. Mesmo no documento Magna Charta Universitatum, em que os princípios republicanos são mais enfatizados, algumas temáticas são introduzidas e estas diferem e se distanciam desses princípios, como é o caso da temática da inovação atrelada ao desenvolvimento da pesquisa na universidade. Com a distância temporal de dez anos, nos referidos documentos, apesar de discutirem concepções similares - as questões referentes à abolição de barreiras, à mobilidade, ao reconhecimento internacional, à política de equivalência -, são introduzidas, com algumas nuanças que anunciam novos desafios e novas demandas para a instituição universitária, necessidades que são ampliadas no contexto de discussão do Processo de Bolonha. 


\section{Universidade no contexto do Processo de Bolonha}

Na Declaração de Bolonha (1999), documento que inicia as discussões relativas ao Processo de Bolonha, é reiterado o discurso, também presente na Declaração de Sorbonne (1998), do papel da universidade no desenvolvimento das dimensões culturais, intelectuais, sociais, científicas e tecnológicas no contexto de alargamento do espaço europeu na perspectiva de uma Europa mais completa e abrangente. A criação da Europa do Conhecimento é colocada como resposta à demanda de formação de determinadas competências exigidas pelo mercado de trabalho globalizado e de valores necessários à criação de um espaço comum.

Nesse contexto, as instituições europeias de ensino superior e as universidades são chamadas a assumirem papel de destaque na construção do espaço europeu de ensino superior e de investigação. Nessa perspectiva, essas instituições são pressionadas no sentido de se adaptarem às necessidades de mudança, principalmente nos aspectos referentes aos avanços do conhecimento científico e seu vínculo com as necessidades de competitividade da economia capitalista europeia. O objetivo consiste em promover a empregabilidade dos cidadãos europeus e elevar a competitividade internacional do sistema europeu de ensino superior em todo o mundo.

Nessa perspectiva, algumas recomendações são indicadas: adoção de um sistema de graus acadêmicos em dois ciclos, ${ }^{7}$ o primeiro com duração de três anos, sendo relevante para o mercado de trabalho europeu, e o segundo ciclo voltado para a obtenção dos graus de mestre e/ou doutor; sistema de créditos ECTS, para a promoção da mobilidade mais ampliada dos estudantes, créditos que podem também ser adquiridos em contextos de ensino não superior, com a condição de que universidades de acolhimento os reconheçam; mobilidade para os estudantes, professores, investigadores e pessoal administrativo; cooperação europeia na avaliação da qualidade, com a utilização de critérios que facilitem a comparação; promoção das dimensões europeias do ensino superior, nos aspectos curriculares, na cooperação institucional, nos esquemas de mobilidade e nos programas integrados de estudos, de formação e de pesquisa.

No tocante à concepção de universidade, são colocadas, na agenda de discussão, algumas temáticas. Uma delas refere-se à necessidade de produção de pesquisa aplicada. Essa temática tem sido predominante nos discursos construídos no contexto do Processo de Bolonha, sendo reiterada, com algumas nuanças, nos documentos que sucedem a Declaração de Bolonha.

No documento que resulta da Convenção das Instituições Europeias de Ensino Superior - a Declaração de Salamanca (2001) -, documento que dá continuidade às discussões do Processo de Bolonha, cujo protagonista consiste nas instituições de 
ensino superior da Europa, são trabalhadas algumas temáticas que visam promover a construção da Área Europeia de Ensino Superior. Nesse sentido, são avaliados as dificuldades e os obstáculos que se colocam na perspectiva dessa construção.

Nesse contexto, as universidades europeias, através de seus representantes, reclamam a definição do seu próprio rumo, no novo contexto europeu, no processo de enfrentamento dos desafios colocados pelas Declarações de Sorbonne e de Bolonha na construção da Área Europeia de Ensino Superior até 2010.

A Declaração de Salamanca é resultado do processo de discussão realizado por doze grupos, os quais debateram seis temas fundamentais sugeridos na Declaração de Bolonha. Os temas são os seguintes: liberdade com responsabilidade; empregabilidade; mobilidade na Área Europeia de Ensino Superior; compatibilidade; garantia e certificação de qualidade; competitividade.

Na discussão da temática liberdade com responsabilidade, as universidades são chamadas a exercerem uma nova liberdade, diante da multiplicidade de tarefas que essa instituição vem assumir no contexto da integração europeia. Nessa perspectiva, a liberdade universitária é entendida como a possibilidade de essa instituição realizar novas parcerias, tanto locais como internacionais, sobretudo parcerias comerciais. Nesse sentido, as universidades precisam de liberdade e de uma maior autonomia para realizar planejamento estratégico em prol do estabelecimento dessas parcerias.

Nesse contexto, a liberdade e a autonomia universitárias são reformuladas, para além do aspecto acadêmico, didático-científico, passando a ser enfatizadas na perspectiva de uma melhor e mais eficiente gestão financeira. Assim, as universidades são pressionadas a buscarem novas receitas através, principalmente, de parcerias com a indústria e com as empresas, sendo a investigação aplicada indicada como a alternativa de conseguir esses novos recursos.

A instituição universitária, no contexto de reformulação da autonomia e da liberdade, passa a ser responsabilizada por: planejamento estratégico, definindo metas e prioridades; distribuição de fundos; seleção das parcerias na produção da pesquisa, na seleção de áreas de pesquisa, na definição de currículos; seleção do pessoal docente; fixação de regulamento na admissão dos estudantes.

Liberdade acadêmica e autonomia, conceitos estes ligados à universidade desde as suas origens (VERGER, 2001; 1999), sofrem reformulações no âmbito das necessidades do desenvolvimento econômico capitalista no contexto da integração europeia. Nesse contexto, a liberdade universitária é compreendida como a possibilidade dessa instituição buscar novas receitas no mercado, através do seu vínculo com o processo produtivo, e a autonomia é reduzida ao aspecto de gestão administrativa 
e financeira. Ambas as reformulações conceituais se inserem no contexto reformulação do papel do Estado no processo de desenvolvimento da educação superior. A autonomia, no que diz respeito à produção de pesquisa e do ensino, fica muito restrita, pois o atendimento das necessidades da economia é colocado como critério de avaliação da produtividade da instituição.

Assim, o tema da empregabilidade é discutido na ótica de a instituição universitária organizar seus programas e currículos de maneira mais diversificada, de modo a atender às necessidades de formação de trabalhadores qualificados em certas competências exigidas pelo mercado de trabalho. Dessa forma, a flexibilidade dos currículos, dos programas de estudo e dos cursos universitários, de maneira a diversificar os pontos de entrada e de saída da instituição, constitui uma exigência demandada pelo setor produtivo.

O tema da mobilidadeé analisado na perspectiva colocada pelos documentos que antecedem o Processo de Bolonha, sendo ampliado na Declaração de Bolonha e na Declaração de Salamanca. Nesse sentido, a mobilidade é pensada para estudantes, professores e pessoal administrativo no contexto de construção da Área Europeia de Ensino Superior.

Para a efetivação da mobilidade, o estabelecimento de determinadas condições é necessário e estas já estão colocadas nos discursos dos documentos anteriores ao Processo de Bolonha: sistema de créditos ECTS, para troca e acumulação; suplemento de diploma; questões relativas ao reconhecimento de títulos; mobilidade virtual e física, sendo que a primeira não substitui a segunda; financiamento de estudantes, professores e pessoal administrativo; sistemas de garantia de qualidade por área de estudo.

As questões referentes à mobilidade adquirem relevância no contexto europeu, pois reclamam a implantação e a resolução de certos aspectos para que seja realmente efetivada. Uma dessas questões diz respeito aos problemas relacionados ao reconhecimento de títulos. Nesse sentido, a qualidade dos cursos universitários constitui um tema recorrente no Processo de Bolonha, sendo necessário o estabelecimento de mecanismos que garantam essa qualidade, facilitando, assim, os processos de reconhecimento. Dessa forma, a efetivação de mecanismos de certificação da qualidade ao nível internacional consiste numa resposta demandada pelos desafios instaurados no processo de construção da Área Europeia de Ensino Superior.

Em relação ao tema da compatibilidade, são discutidas questões referentes à estruturação dos cursos, de maneira que se constitua uma base comum de qualificação. Assim, a estruturação dos cursos universitários em dois ciclos, sendo os cursos de graduação organizados com base em créditos ECTS, é indicada como recomendação na Declaração de Salamanca, já enfatizada nos documentos anteriores. 
O tema da competitividade é analisado na perspectiva de que as universidades precisam de uma maior liberdade operacional para planejar programas de estudos, cursos que possam atrair estudantes do mundo inteiro. Nesse sentido, a competitividade é pensada dentro e fora da Área Europeia de Ensino Superior. Para isso, a qualidade dos cursos é necessária num contexto de luta por conquista de estudantes, sendo imprescindível uma maior autonomia de gestão administrativa e financeira das instituições.

No documento que resulta da Conferência de Praga (2001), assinado pelos ministros europeus do ensino superior, são discutidos os temas relativos à educação transnacional e à responsabilidade dos governos em relação ao ensino superior. No contexto de globalização e de integração europeia, a educação é pensada em termos transnacionais e, nesse sentido, mesmo com a reformulação do papel do Estado, este é chamado, no documento em tela, a não se abster de sua responsabilidade em relação ao ensino superior.

Nessa perspectiva, no referido documento, são sugeridas recomendações: adoção do sistema de créditos e de dois ciclos na organização dos cursos acadêmicos, para facilitar a comparabilidade; reconhecimento; competitividade e empregabilidade. Essas orientações não constituem novidade, pois se inserem no contexto de discussão do Processo de Bolonha.

Na Declaração de Göteborg (2001), documento construído pelo movimento estudantil europeu, representado pelo The National Unions of Students in Europe (Esib), os estudantes participam da discussão concernente à construção da Área Europeia de Ensino Superior. Assim, são analisados alguns temas principais: a responsabilidade dos países europeus e o papel dos governos no desenvolvimento dos sistemas nacionais de ensino superior.

Nesta Declaração, os estudantes europeus recomendam: cooperação e solidariedade dos Estados europeus no desenvolvimento do ensino superior; estabelecimento do sistema de créditos; cooperação europeia no processo de garantia da qualidade dos sistemas nacionais; mobilidade e questões referentes à promoção cultural e à tolerância.

Percebe-se, no discurso dos estudantes, uma maior ênfase em relação à responsabilidade dos Estados no desenvolvimento do ensino superior, sendo estes pressionados a exercerem um papel fundamental no contexto de integração e de concretização de governos supranacionais.

No referido documento, a concepção de universidade que predomina no discurso dos estudantes é aquela que a considera, sobretudo, como um bem público, a ser desenvolvido e financiado pelos Estados, mesmo se, na prática, o que se observa 
é o pleno processo de integração europeia. Nessa perspectiva, os governos são pressionados a não se absterem de sua responsabilidade em relação às instituições de ensino superior, sobretudo no tocante ao financiamento.

No documento Promovendo o Processo de Bolonha (2001), de autoria de Pedro Lourtie, na reunião ministerial de Praga, é dado prosseguimento à discussão colocada na Declaração de Bolonha (1999), tais como as questões relativas à construção da Área Europeia de Ensino Superior no contexto de uma educação transnacional. Nessa perspectiva, são recomendados: sistema de créditos; estrutura de graus em dois ciclos; garantia de qualidade e acreditação; mobilidade e comparabilidade de formação.

No documento em análise, a concepção de universidade defendida se insere no contexto de discussão colocada pela Declaração de Bolonha (1999). Na sociedade contemporânea, em que a produção de conhecimento e sua aplicabilidade ganham relevância diante das demandas de competitividade da economia europeia, as universidades são conclamadas a participarem desse processo, contribuindo na formação de competências exigidas pelo mercado de trabalho e na produção de pesquisa com potencial de aplicação pela indústria. Percebe-se um distanciamento em relação ao modelo de Humboldt de universidade e dos ideais republicanos, pois a liberdade, a autonomia e a investigação universitárias passam cada vez mais a se vincularem aos imperativos das necessidades da economia. Os aspectos acadêmicos, sobretudo aqueles referentes à autonomia didática e científica, à liberdade de ensino e de pesquisa e ao desenvolvimento da pesquisa básica, aspectos estes que distinguem uma instituição universitária, perdem relevância e passam a ser marginalizados no processo de desenvolvimento social e econômico ${ }^{8}$ em curso.

No Comunicado da Comissão das Comunidades Europeias (2003), documento elaborado no contexto do Conselho Europeu, as universidades, entendidas, no referido documento, como todos os estabelecimentos de ensino superior, são pressionadas a exercerem um papel de destaque na integração europeia. Nessa perspectiva, as instituições universitárias são chamadas a produzirem novos conhecimentos e a utilizarem os resultados de suas pesquisas em processos industriais. Percebe-se que os temas relativos à investigação aplicada e à inovação são trabalhados no discurso do supracitado Comunicado, como também nos discursos dos documentos anteriores, sendo, portanto, uma temática que domina as discussões relativas ao papel da universidade na sociedade contemporânea, discussões estas que terminam por reformular as tarefas tradicionais da instituição universitária. Diante das novas necessidades da economia, a produção do conhecimento na universidade volta-se para a possibilidade de sua exploração comercial, pois o que passa a ser relevante é o processo de inovação constante. 
Nesse sentido, uma maior diferenciação dos sistemas de ensino superior é indicada como uma recomendação. Assim, algumas instituições se concentram na formação de determinadas competências demandadas pelo mercado de trabalho e outras, na produção de pesquisa, cujos resultados possam ser explorados pela economia.

Outras recomendações são sugeridas: cooperação entre universidades e empresas, voltada para a inovação; compatibilidade e transparência dos sistemas de reconhecimento de qualificações; mobilidade; projeção do universo acadêmico europeu em todo o mundo, onde as universidades europeias se tornem referência internacional.

Na Declaração de Graz (2003), documento construído pela Convenção da Associação Europeia da Universidade, as universidades são consideradas instituições de destaque no desenvolvimento da sociedade europeia, na perspectiva de criação e transmissão de conhecimento, como também na promoção da cultura e dos valores europeus. Dessa forma, as universidades têm como foco de atividade a produção de pesquisa no contexto do processo de construção da Europa do Conhecimento e da Investigação. Nessa construção, algumas recomendações são indicadas: consolidação do sistema de créditos ECTS; suplemento ao diploma; mobilidade; qualidade acadêmica; garantia de qualidade; autonomia institucional, atrelada a esquemas de responsabilização das universidades, no que se refere à realização de suas atividades habituais, tais como ensino e pesquisa.

Percebe-se que o tema da autonomia é discutido na perspectiva de sua redução para o aspecto administrativo e financeiro. A autonomia universitária na produção da pesquisa não é considerada, pois a necessidade de inovação e a investigação aplicada ganham maior relevância no contexto de competitividade global.

No documento intitulado Comunicado de Berlim (2003), que resulta da Reunião Ministerial de Berlim, as temáticas relativas àinvestigação aplicada, à inovação e ao desenvolvimento dadimensão europeia no ensino superior predominam no discurso em referência. Nessa perspectiva, no contexto de construção da Europa do Conhecimento e da Área Europeia de Investigação, a qual constitui alicerce fundamental da anterior, o papel das instituições de ensino superior ganha relevância no processo de desenvolvimento da economia europeia, sendo pressionadas a produzirem conhecimentos passíveis de serem explorados pelas necessidades do desenvolvimento econômico.

No contexto de construção da Área Europeia de Ensino Superior e da Investigação, o modelo cultural e social dominante, a ser disseminado nas e pelas instituições, consiste no modelo europeu. A discussão referente ao desenvolvimento das dimensões europeias se encontra presente desde o início do Processo de Bolonha, 
sendo, portanto, um tema recorrente e utilizado como um instrumento de atração de estudantes do mundo inteiro.

O Processo de Bolonha constitui uma referência no debate empreendido pelos diferentes interlocutores da reforma, no Brasil, não obstante os documentos referentes a esse processo se relacionarem ao contexto europeu. A produção da inovação tecnológica pela universidade, em parceria com o setor produtivo, consiste numa ideia-força no movimento de reforma em curso, ensejando a publicação da Lei de Inovação Tecnológica, Lei n. 10.973, de 2 de dezembro de 2004, e da Lei da Parceria Público-Privada, Lei n. 11.079, de 30 de dezembro de 2004, para dar suporte legal ao projeto de inovação tecnológica respaldado nestas parcerias.

Quanto às recomendações para a efetivação da reforma da educação superior brasileira, algumas orientações advêm do contexto europeu, dado este revelador do alto grau de heteronomia do referido campo, entendida em relação a dois aspectos: a influência de organismos internacionais na proposição de políticas de educação superior e a definição da agenda da universidade por agentes e instituições e critérios exteriores a sua lógica institucional (SGUISSARDI, 2006; TRIGUEIRO, 2003). Mas isso não significa dizer que, no processo de reforma em curso, as temáticas, concepções e orientações colocadas na agenda de debate político traduzam a mera importação de modelos. No caso brasileiro, presencia-se a ocorrência de uma dinâmica, no interior do campo, em que temas globais e específicos se relacionam na configuração do papel da educação superior e da universidade a partir da segunda metade da década de 1990.

\section{Notas}

1. O Processo de Bolonha consiste nas atividades desenvolvidas a partir da Declaração de Bolonha, voltadas para a concretização da reforma dos sistemas de ensino superior europeus. Essa Declaração tem como protagonistas 29 ministros da Educação da Europa, que, em reunião ministerial realizada em Bolonha, em 1999, decidiram pela construção da Área Europeia de Ensino Superior até 2010. Os desdobramentos da Declaração de Bolonha constituem o Processo de Bolonha.

2. A abertura definitiva das fronteiras no contexto da integração europeia se concretizou em 1992, momento de conclusão do processo que resultou no Mercado Único, quatro anos depois da construção do documento Magna Charta Universitatum (1988). Neste, os reitores debatem a integração europeia e o papel das universidades nesse processo.

3. O processo de integração europeia se dá, primeiramente, pelo viés da integração econômica. Assim, são criados, pelo Tratado de Paris (1951), a Comunidade Europeia do Carvão e do Aço (Ceca), e, pelo Tratado de Roma (1957), a Comunidade Econômica Europeia (CEE). O processo atual de construção de uma Europa mais abrangente abarca outras dimensões, como, por exemplo, o processo de integração sob o viés educacional. Os documentos, aqui analisados, construídos por diferentes protagonistas, se inserem no contexto de alargamento das fronteiras e de integração sob a base de uma política educacional comum que ressalte evalorize a dimensão europeia. Sobre os antecedentes da União Europeia, ver Seitenfus (2005).

4. No caso do discurso da Organização das Nações Unidas para a Educação, a Ciência e a Cultura (Unesco), essa discussão é colocada de forma específica, pois o tema do desenvolvimento não é 
tratado, unicamente, sob o viés econômico, mas abarca as dimensões sociais e culturais. Além disso, a Unesco tem assumido a defesa, ao nível mundial, de um desenvolvimento sustentável. A universidade, nesse contexto, assume papel fundamental na promoção do desenvolvimento sustentável.

5. O sistema de créditos europeus, conhecido como ECTS, é anterior ao Processo de Bolonha, sendo elaborado com o intuito de facilitar a concretização do Programa Erasmus, criado em 1988 para favorecer a mobilidade dos estudantes europeus. A discussão atual coloca a questão da ampliação do uso desse sistema para todos os cursos de ensino superior da Europa e, também, a sua utilização para a troca no contexto de mobilidade mais ampliada.

6. Não somente tarefas diferentes daquelas que tradicionalmente as universidades são chamadas a desempenhar, e que são avaliadas socialmente. Mesmos nas tarefas tradicionais, como, por exemplo, a atividade de pesquisa, as instituições universitárias são cobradas no sentido de reformular essas tarefas. Nesse sentido, a investigação científica, desenvolvida por essas instituições, deve estar voltada para a pesquisa aplicada e seu vínculo com a indústria e outras empresas ganha relevância no contexto de competitividade da economia capitalista ao nível global.

7. A discussão sobre o sistema de graus do ensino superior não é nova, mas é retomada no contexto de integração europeia e de reformulação dos sistemas de ensino superior e da universidade no processo de construção da Europa do Conhecimento ou do Saber. Nesse sentido, a adoção de dois ciclos é colocada como proposta que visa facilitar a mobilidade dos estudantes, as necessidades de comparação dos sistemas de ensino e as demandas de qualificação do mercado de trabalho europeu.

8. A marginalização não só ocorre em termos do que é relevante para as necessidades da economia, mas também, e principalmente, ao nível dos discursos sobre o papel da universidade na sociedade contemporânea. Nesse sentido, as temáticas supracitadas não adquirem importância ou não apresentam o mesmo peso no processo de discussão das propostas de reforma da universidade.

\section{Referências}

SEITENFUS, R. Manual das organizações internacionais. 4. ed. Porto Alegre: Livraria do Advogado, 2005.

SGUISSARDI, V. Reforma universitária no Brasil - 1995-2005: precária trajetória, incerto futuro. Educação E Sociedade, Campinas, v. 27, n. 96, p. 1021-1056, out. 2006.

TRIGUEIRO, M.G.S. Reforma universitária e mudanças no ensino superior no Brasil. Iesalc/Unesco, 2003.

TRINDADE, H. A República em tempos de reforma universitária: o desafio do governo Lula. Educação \& Sociedade, Campinas, v. 25, n. 88, p. 819-844, out. 2004.

VERGER, J. Homens e saber na Idade Média. Trad. de Carlota Boto. Bauru: Edusc, 1999.

VERGER, J. Cultura, ensino e sociedade no Ocidente nos séculos XII e XIII. Trad. de Viviane Ribeiro. São Paulo: Edusc, 2001. 


\section{Documentos}

ACADEMIA BRASILEIRA DE CIENCIAS (ABC). Subsídios para a reforma da educação superior. Brasília, DF, nov. 2004.

BRASIL. Lei n. 10.973, de 2 de dezembro de 2004. Dispõe sobre incentivos à inovação e à pesquisa científica e tecnológica no ambiente produtivo e dá outras providências. Diário Oficial da União, Brasília, DF, 3 dez. 2004.

BRASIL. Lei n. 11.079, de 30 de dezembro de 2004. Institui normas gerais para licitação e contratação de parceria público-privada no âmbito da administração pública. Diário Oficial da União, Brasília, DF, 31 dez. 2004.

COMISSÃO DAS COMUNIDADES EUROPEIAS. O papel das universidades na Europa do conhecimento. Bruxelas, 2003.

COMMUNIQUÉ OF THE CONFERENCE OF MINISTERS RESPONSIBLE FOR HIGHER EDUCATION. Berlim, 2003. Disponível em: <http://www.bolognaberlin2003.de/pdf/Communique1.pdf $>$. Acesso em: 20 fev. 2006.

COMMUNIQUÉ OF THE MEETING OF EUROPEAN MINISTERS IN CHARGE OF HIGHER EDUCATION.A caminho da área europeia de ensino superior. Praga, 2001. Disponível em: <http://www.utl.pt/docs/ComunicadodePraga.pdf>. Acesso em: 10 fev. 2006.

CONVENTION OF EUROPEAN HIGHER EDUCATION INSTITUTIONS. Declaração de Salamanca. Zürich, 2001. Disponível em: <http://www.anped11.uerj.br>. Acesso em: 10 fev. 2006.

DECLARAÇÃO CONJUNTA DOS MINISTROS DA EDUCAÇÃO EUROPEUS. Declaração de Bolonha. Bolonha, 1999. Disponível em: <http://www.dges.mctes.pt/NR/ rdonlyres/5FE89836-7A33-4FA6-994A-D7E7A841BAA5/1818/Declaracao_Bolonha_ portugues.pdf>. Acesso em: 10 fev. 2006.

DECLARAÇÃO CONJUNTA DE QUATRO MINISTROS DE ENSINO SUPERIOR EUROPEU (Alemanha, França, Itália e Reino Unido). Harmoniser l'architecture du systèmeeuropé em d’enseignementsupérieur.Paris, 1998. Disponível em: <http://www.utl. pt/docs/ DeclaracaoSorbonne.pdf $>$. Acesso em: 10 fev. 2006.

GRAZ DECLARATION. Forward from Berlin: the role of universities. Bruxelles: EUA, 2003.

LOURTIE, P. A declaração de Bolonha e o sistema de graus do ensino superior: bases para uma discussão. Disponível em: <http://www.anped11.uerj.br>. Acesso em: 10 fev. 2006. 
LOURTIE, P. Furthering the Bologna Process; report to the Ministers of Education of the signatory countries. Prague, 2001.

MINISTÉRIO DA CIÊNCIA E DO ENSINO SUPERIOR. Conferência de ministros responsáveis pelo ensino superior. Berlim, 2003. Disponível em: <http://www.anped11. uerj.br>. Acesso em: 10 fev. 2006.

NATIONAL UNIONS OF STUDENTS IN EUROPE (ESIB). Student Göteborg declaration. Belgium, 2001. Disponível em: <http://www.utl.pt/docs/DeclaracaoSorbonne. pdf>. Acesso em: 10 fev. 2006.

REITORES DAS UNIVERSIDADES EUROPEIAS. Magna Carta das Universidades. Bolonha, 1988. Disponível em: <http://www.esta.ipt.pt/3es/download/Magna\%20Carta \%20das\%20Universidades.pdf $>$. Acesso em: 10 fev. 2006.

Recebido em 30 de abril de 2010.

Aprovado em 30 de dezembro de 2011. 